\title{
Métodos Numéricos de Alta Resolução Aplicados em Problemas de Interação Choque-Turbulência
}

\author{
Brener L. O. Ramos (IC), William R. Wolf (PQ)
}

\begin{abstract}
Resumo
O presente projeto de pesquisa aborda o estudo de métodos numéricos de alta resolução e sua aplicação em problemas que representam os mecanismos físicos de interação choque-turbulência. Equações diferenciais parciais lineares e não-lineares foram resolvidas com condições iniciais e de contorno representativas do problema de interação choque-turbulência. Métodos de diferenças finitas compactos de alta ordem foram aplicados para resolver essas equações juntamente com filtros compactos para altos números de onda, além de métodos clássicos de diferenças finitas. Além disso, métodos essencialmente não-oscilatórios (ENO e WENO) também foram aplicados para a captura das ondas de choque.
\end{abstract}

Palavras Chave: interação choque-turbulência, métodos compactos, métodos não-oscilatórios

\section{Introdução}

Escoamentos compressíveis de alta velocidade apresentam gradientes elevados de propriedades que surgem na forma de ondas de choque. Ao mesmo tempo, esses escoamentos são usualmente turbulentos e, portanto, ocorrem interações choque-turbulência. Esse tipo de interação é comum em problemas de camadaslimite supersônicas que se desenvolvem sobre asas de aeronaves ou em bocais de foguetes, onde ocorre a formação de ondas de choque internas. Este projeto de pesquisa tem como objetivo o estudo e a implementação de métodos numéricos pertinentes às simulações de escoamentos como os descritos acima. Ao final do trabalho, foram implementados e comparados os seguintes métodos numéricos: UPWIND, CENTRADO, COMPACTO com filtro de alta ordem, ENO e WENO. É importante salientar que, dos métodos citados, os dois últimos são métodos dedicados à captura de choque bastante modernos, atualmente sendo alvo de muitas pesquisas.

\section{Resultados e Discussão}

Foram feitos testes com as equações de convecção linear e equação de Burgers, nãolinear. Para fazer as simulações, foram usadas as seguintes condições iniciais: uma função senoidal, um degrau e um pulso. A função senoidal teve como objetivo verificar 0 comportamento dos métodos para uma região de oscilação suave, o degrau para uma região de gradiente elevado (como uma descontinuidade) e o pulso seria uma condição intermediária, facilmente dissipada por métodos de baixa ordem.
Após os testes, foi verificado que para regiões de oscilação suave os métodos CENTRADO, COMPACTO com filtro de alta ordem e WENO obtiveram soluções muito satisfatórias. Já para um degrau, o método WENO foi o mais apropriado, sendo o esquema que mais preservou o gradiente elevado. Por fim, na condição inicial tipo pulso, o método COMPACTO com filtro de alta ordem foi o mais apropriado, sendo o que mais preservou a forma do pulso à medida que este propagava.

\section{Conclusões}

Após analisar os resultados, ficou evidente que para uma interação choque-turbulência, um método numérico composto pelos esquemas COMPACTO com filtro de alta ordem e WENO seria ideal para simulações numéricas envolvendo esse fenômeno físico. Nas regiões de oscilações mais suaves, o método COMPACTO com filtro de alta ordem seria mais apropriado, pois ele gera uma solução satisfatória e a um custo computacional baixo. Já o esquema WENO seria empregado nas regiões de gradientes elevados, pois ele consegue capturar muito bem esse tipo de fenômeno.

\section{Agradecimentos}

Gostaria de agradecer a minha família, amigos e meu orientador, William, quem me deu essa oportunidade. Agradeço também à UNICAMP pelo financiamento através da bolsa PIBIC.

\footnotetext{
1 Lomax, H.; Pulliam T. H.; Zingg, D. W. Fundamentals of Computational Fluid Dynamics, Springer 1999

${ }^{2}$ Lele S. K. Compact Finite Difference Schemes with Spectral-like Resolution, Journal of Computational Physics 1991

${ }^{3}$ Shu C. W. Essentially Non-Oscillatory and Weighted Essentially Non-Oscillatory Schemes for Hyperbolic Conservation Laws, Journal of computational Physics 1997
} 